\title{
COMPOSICIONES BARROGAS DE DOS PINTURAS EN EL ALTAR DEL PERDÓN
}

\author{
Por Justino Fernández
}

LAS ESTRUCTURAs o trazados de las composiciones pictóricas tienen un interés fundamental y su estudio es indispensable si es que se pretende llevar al cabo análisis formales completos. Por otra parte, como no son ajenas a las concepciones totales de las obras, están intimamente ligadas a lo significado en ellas. Así, los análisis formales ayudan a comprender las intenciones de los artistas y cómo han logrado ciertos efectos a base de composiciones bien estructuradas.

Hace tiempo que estudié las composiciones barrocas de algunas pinturas de la Nueva España (Anales 28, 1959). El mero cotejo en despliegue es revelador de ciertos procedimientos de unas épocas y otras. Cuando se logre estudiar así un número importante de pinturas, se podrán alcanzar varias conclusiones que iluminen la comprensión de nuestra pintura llamada "colonial".

Añado a las ya estudiadas dos pinturas más, y bien importantes, el San Sebastian y la Virgen con el Niño, que se encuentran en el Altar del Perdón, de la Catedral Metropolitana, y que pertenecen al siglo xvı.

Sólo me ocupo de las estructuras de sus composiciones, como una contribución a su estudio integral; ${ }^{1}$ quedan fuera las discusiones sobre su origen y la identificación de su posible autor o autores, así como el estudio formal, iconográfico y comparativo completo; la parte histórica en relación con ellas; sus valores y los sitios que puedan ocupar en la historia del arte de la Nueva España. Todo eso debe ser investigado y estudiado, teniendo en cuenta las opiniones y datos que ya se han publicado, pero no todo es posible realizarlo por ahora. ${ }^{2}$ El San Sebastián en el Altar del Perdón de la Catedral Metropolitana.

Estructura. El eje vertical al centro del cuadro marca la verticalidad de la pierna izquierda y limita el rostro. El eje horizontal marca al

1. Las imperfecciones de los trazos en las ilustraciones se deben a que las fotografías no corresponden a las dimensiones exactas de las pinturas, pero ello no invalida el estudio de las estructuras en lo fundamental.

2 Véanse: Toussaint, Proceso y denuncia contra Simón Pereyns... Anales 2, 1938, Suplemento; Arte Colonial en México, 1962, 2* ed. Pintura Colonial en México, 1965. Kubler y Soria, Art and Architecture in Spain and Portugal... Pelican (1959). 
centro del cuadro. El movimiento de los hombros está réido por una diagonal, en la parte superior del cuadro, y su contraria marca un punto visual de importancia, sobre el hombro izquierdo. El árbol al lado izquierdo del cuadro se rige por una diagonal que va hacia abajo, desde el nivel del ojo de la figura; la contraria, es virtual, pero a ella se ajustan ciertos accidentes del paisaje. Estas dos diagonales, que forman un triángulo invertido cuyo vértice queda fuera del límite inferior del cuadro, tienen por función abrir la composición hacia la parte superior y más significativa del tema. Una gran curva rige el movimiento del torso, hasta el mentón, y se prolonga por la parte superior hasta el claro en el cielo; por la parte inferior una contracurva se prolonga hasta la rodilla derecha y el tronco del árbol. Podrian trazarse otras diagonales secundarias, pero no son indispensables.

Significativamente el gran triángulo invertido atrae la atención hacia la parte superior, donde se encuentra el torso, éste cargado al lado izquierdo. La curva superior pone en relación el movimiento del torso, y la mirada del Santo sacrificado con el claro que es una apertura en el obscuro cielo y sugerencia del más allá, a donde vuelve la mirada el Santo, con sentido de esperanza. La curva inferior pone en relación las partes del cuerpo con el tronco de árbol, éste -como en la tradición de la pintura occidental- simbolo de virilidad. Así, las curvas ponen en relación lo terrenal y lo celestial, a través del cuerpo de San Sebastián que se encuentra entre lo uno y lo otro en la tragedia, y que se subraya por el dramático fondo de paisaje y celaje, que recuerda vagamente algunas obras de Tintoretto.

Si se compara la estructura de San Sebastián con otras composiciones barrocas de la pintura de la Nueva España (Anales 28, 1959), se notará que los ejes en diagonales, que forman triángulos abiertos, son frecuentes; al mismo tiempo que señalan una dirección que interesaba subrayar al artista, dan cierto dinamismo a las composiciones. La particularidad de la estructura de San Sebastián consiste en el triángulo fundamental de la composición, que es invertido, y en las curvas que rigen el torso, que además de dar movimiento al cuerpo hacen que éste adquiera mayor significación; no son curvas tan sólo ornamentales o para dar un sentido sensual.

La Virgen con el Niño en el Altar del Perdón de la Catedral Metropolitana.

Estructura. El eje vertical al centro del cuadro pasa exactamente por la joya central de la corona. El eje horizontal se cruza con el anterior 
DOI: http://dx.doi.org/10.22201/iie.18703062e.1966.35.816

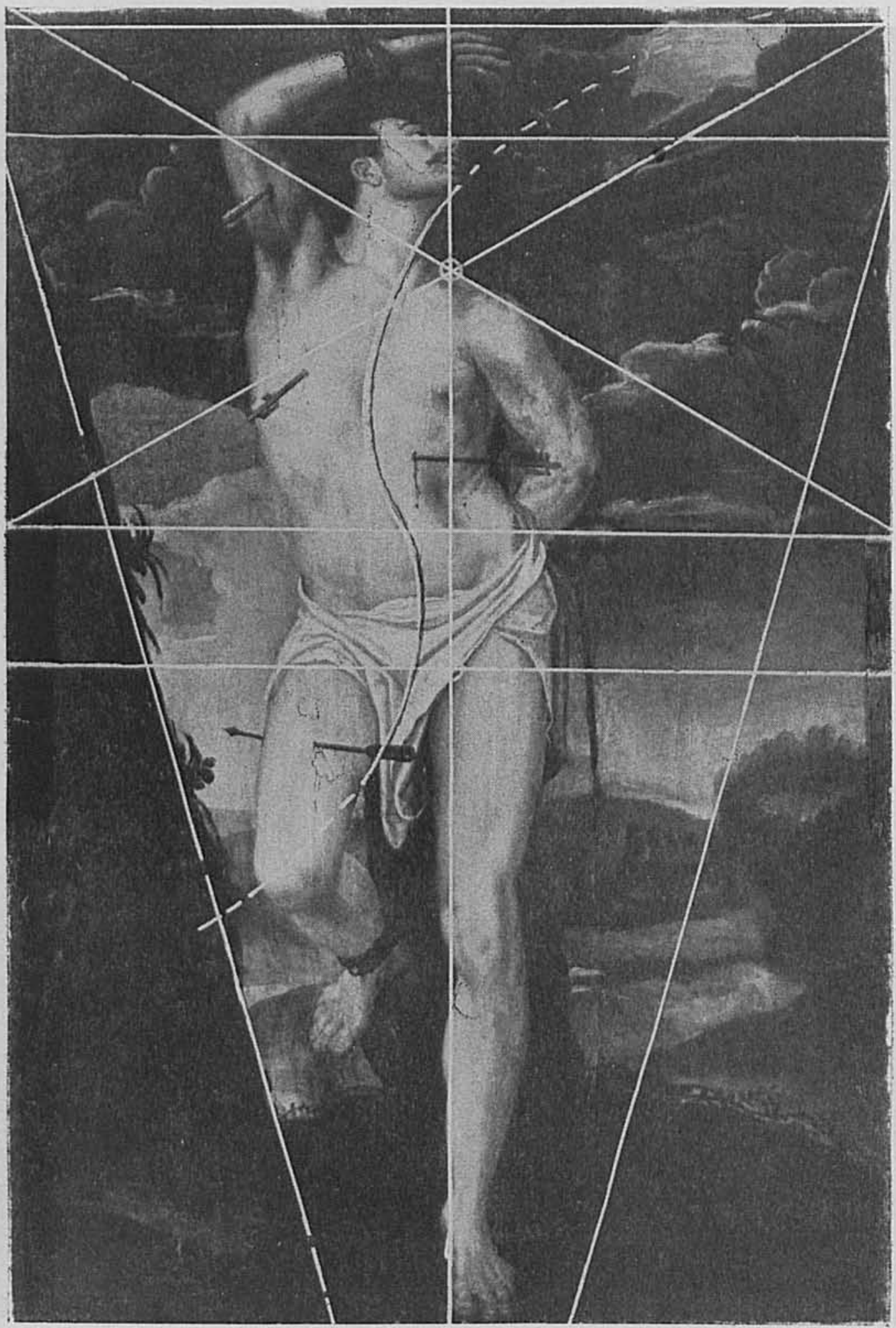

1. San Sebastian. Oleo sobre tabla, siglo xvi. Catedral Metropolitana. 
DOI: http://dx.doi.org/10.22201/iie.18703062e.1966.35.816

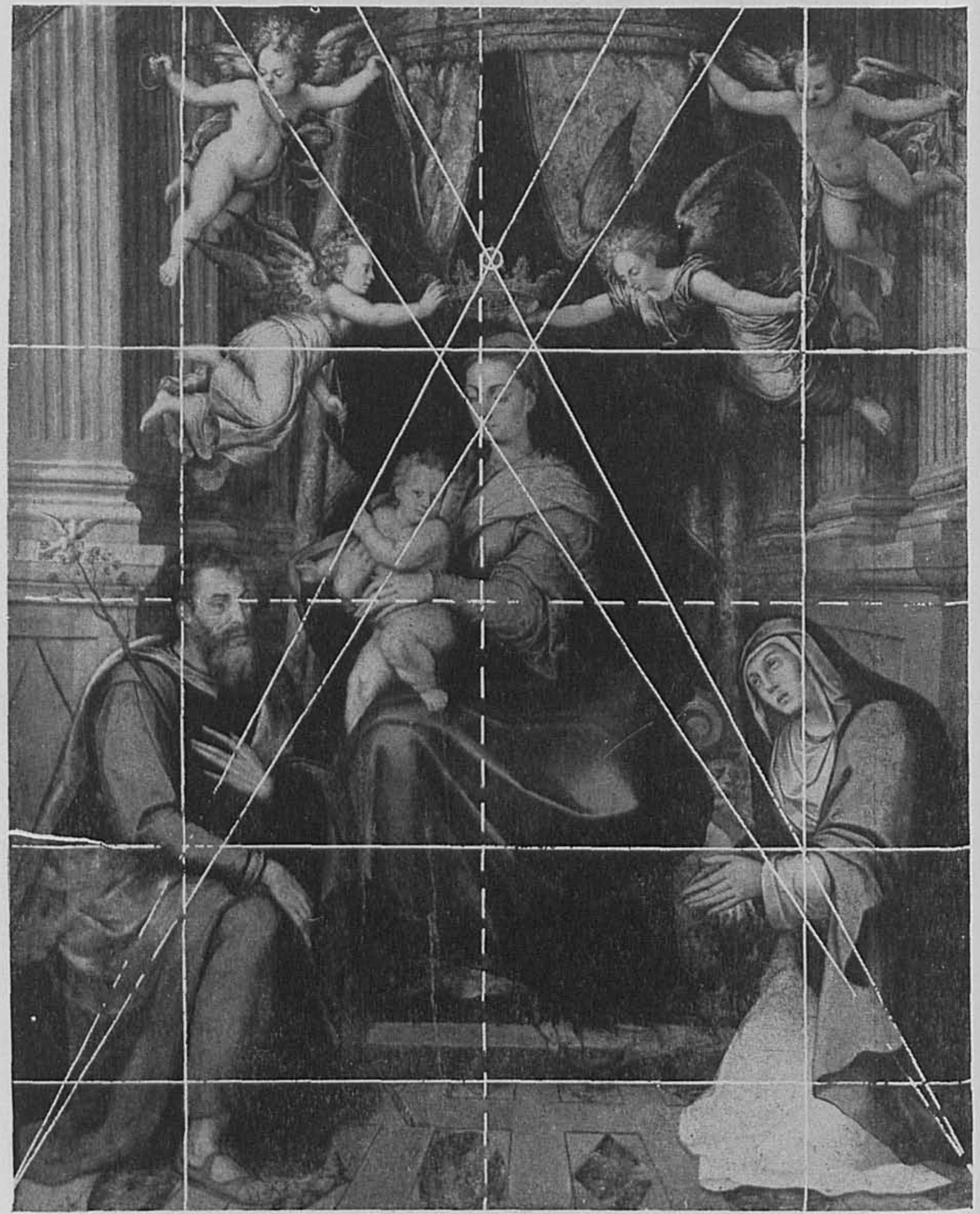

2. Virgen con el Niño. Óleo sobre tabla enlienzada, siglo xv. Catedral Metropolitana. 
en el brazo izquierdo de la Virgen. Diagonales a derecha e izquierda forman un triángulo, dentro del cual, quedan inscritas las imágenes de la Virgen y el Niño, cuyo vértice se encuentra en la joya central de la corona y su base en el límite inferior del cuadro. La prolongación de las diagonales en la parte superior rigen el dosel y las manos de los ángeles. Éstos parecen estar organizados a base de dos curvas concéntricas virtuales colgantes, pero a las que no se ajustan con rigor. Dos ejes verticales a uno y otro lado del central y equidistantes del mismo pasan por los brazos de las figuras a ambos lados de la parte inferior de la composición; el eje de la izquierda limita los ángeles de este lado. Un eje horizontal en la parte baja pasa por los brazos de las dos figuras arrodilladas; el eje superior correspondiente pasa por el tocado de la Virgen. Otro eje horizontal en la parte inferior marca el escalón de la plataforma sobre la que se encuentra el trono de la Virgen.

La forma piramidal que estructura y limita el grupo de la Virgen y el Niño le da significación e importancia, pues la atención se enfoca centralmente en las divinas personas, en la parte superior del triángulo. La mitad superior del cuadro está destinada al mundo ultraterreno, celestial o divino; la mitad inferior al mundo terrenal, con la imagen de San José del lado izquierdo y otra imagen, no identificada (¿Santa Ana?), al lado derecho, ambas arrodilladas en actitud de adoración. Así, quedan bien definidos los campos, mas, sin embargo, la cabeza de San José invade la zona celestial y, en cambio, las piernas del Niño la terrenal, como también medio cuerpo de la Vigen. De esa manera queda sugerida su participación en ambos mundos. Las imágenes inferiores, a derecha e izquierda, subrayan la forma piramidal, si bien sus partes principales se encuentran fuera de ella, salvo las manos, y hasta su tratamiento pictórico, duro y con los paños un tanto acartonados, difiere del grupo central y de los ángeles, mucho más finos, salvo el manto de la Virgen que cubre sus piernas. Todo ello fue intencional en el artista y aunque desconcierta a primera vista, se comprende la distinción entre ambos mundos que quiso marcar, y que le resta unidad a la pintura.

La esbeltez de la parte superior de la imagen de la Virgen, y la arquitectura en perspectiva sugieren un incipiente manierismo. Si se compara este tipo de composición piramidal con otras semejantes (Anales 28, 1959), no obstante las diferencias, de la pintura barroca de la Nueva España, por ejemplo, con la Adoración de los Reyes, de José Juárez, 1655 , se verá que no es de excepción en lo fundamental, además de que tiene larga tradición desde la pintura renacentista. 